\title{
Proteases and Oxidants in Experimental Pulmonary Inflammatory Injury
}

\author{
Ingrid U. Schraufstätter, Susan D. Revak, and \\ Charles G. Cochrane \\ Department of Immunology, Scripps Clinic and Research \\ Foundation, La Jolla, California 92037
}

bstract. We have examined various biochemical parameters of pulmonary inflammation in experimental animals. Intrabronchial instillation of glucose oxidase-glucose $(\mathrm{GO} / \mathrm{G})$ to produce oxidants or formylated norleu-leu-phe (FNLP) or phorbol myristate acetate (PMA) as leukocytic stimuli induced severe acute pulmonary injury in New Zealand white rabbits. PMA also induced inflammation when administered intravenously. Each stimulus induced transudation of protein from the vascular space into the pulmonary tissues, and an influx of leukocytes during the 4-6 h period of the experiment. Pathophysiologic changes were measured by edema formation (transudation of ${ }^{125} \mathrm{I}$-bovine serum albumin), and histologic examination. Biochemical analysis was performed by measuring concentrations of potentially injurious agents in bronchoalveolar lavage (BAL) fluid. Increased acid protease and myeloperoxidase levels were found in the BAL fluid after administration of either of the stimuli.

Evidence of oxidant generation in vivo was obtained in two different ways. In the first, specific activities for catalase were measured in the BAL fluid in the presence or absence of 3-amino, 1,2,4 triazole (AT), injected at intervals before obtaining BAL fluid. In the presence of AT, specific activities for catalase dropped to 0.22 after a double instillation of FNLP and to 0.15 in the presence of GO/G. In neutrophil-depleted FNLP animals, catalase was not greatly inhibited by AT (sp act 0.90 ).

In the second, intracellular levels of total glutathione

This is publication no. 3074-IMM from Department of Immunology of Scripps Clinic and Research Foundation.

Dr. Schraufstätter is a Parker B. Francis Foundation Fellow in Pulmonary Research.

Received for publication 9 August 1983 and in revised form 8 December 1983.

J. Clin. Invest.

(C) The American Society for Clinical Investigation, Inc. 0021-9738/84/04/1175/10 \$1.00

Volume 73, April 1984, 1175-1184
(GSH + GSSG) in whole lung tissue and alveolar macrophages decreased when stimuli of neutrophils were administered. Intrabronchially instilled PMA, e.g., caused a drop of glutathione in whole lung tissue from the control value of $2.3 \mu \mathrm{mol} \mathrm{GSH}$ equivalent/100 mg dry wt to 0.54 $\mu \mathrm{mol}$ GSH equivalent/100 mg dry wt at $4 \mathrm{~h}$. Neutrophil depletion and superoxide dismutase protected from this effect. From these results, we conclude that $\mathrm{O}_{2}^{-}$or its metabolites can initiate severe pulmonary injury as shown by the effect of GO/G and that, during development of pulmonary injury, stimulated neutrophils generate oxidants and release proteolytic enzymes into the surrounding tissues.

\section{Introduction}

Inflammation is the product of cellular and humoral effectors. Evidence recently obtained from patients with acute respiratory distress syndrome in both adults and neonates, in whom many general features of pulmonary inflammation are condensed over a short period of time, indicated that at least two important pathogenic effectors were present in the pulmonary tissues. These were neutrophil elastase (1-3) and oxidants (4). The presence of these has also been demonstrated in chronic pulmonary inflammation: lavage fluids from cigarette smokers contained active neutrophil elastase, which was not bound to $\alpha_{1}$-proteinase inhibitor $\left(\alpha_{1}-\mathrm{PI}\right),{ }^{1}$ because the latter is easily oxidized at the active site and inactivated (5-7). Both leukocyte elastase and oxidants, administered exogenously, have been shown to lead to severe pulmonary injury in experimental animals $(8,9)$. Intravenous perfusion of rabbit lungs with normal human neutrophils stimulated with phorbolester also induced severe inflammatory injury, whereas perfusion with similarly treated neutrophils from patients with chronic granulomatous disease did not (10).

1. Abbreviations used in this paper: AT, 3-amino, 1,2,4 triazole; BAL, bronchoalveolar lavage; ELISA, enzyme-linked immunosorbent assay; FNLP, formyl-norleu-leu-phe; GO/G, glucose oxidase-glucose; $\alpha_{1}$-PI, $\alpha_{1}$-proteinase inhibitor; PMA, phorbol myristate acetate; PMN, polymorphonuclear neutrophil; SOD, superoxide dismutase. 
Activation of the complement system with cobra venom factor or thermal injury induced an increase in pulmonary vascular permeability in rats which could be prevented by neutrophil depletion $(11,12)$. Partial protection from pulmonary injury was observed when hydroxyl radical scavengers were administered (13).

In these studies, however, information has not been provided as to whether effector (mediating) systems were generated in situ by the treatment within the experimental animal. Evidence that stimulated leukocytes do produce oxidants in vivo is lacking. It is also unclear as to whether generation of oxidants in the lung can induce protease release and vice versa. Without information regarding the question of whether specific mediators are generated and whether these stimulate release of other mediators, it is not possible to define the role of each in the pathogenesis.

To gain more information about the biochemical processes involved in pulmonary inflammation, we have employed a rabbit model using as inciting agents, either glucose oxidase-glucose $(\mathrm{GO} / \mathrm{G})$ to produce directly oxidants, or formylated norleu-leuphe (FNLP) or phorbol myristate acetate (PMA) as leukocytic stimuli. Bronchoalveolar lavage (BAL) fluids were then obtained to measure the presence of leukocytic enzymes, especially proteases, and evidence of oxidant generation in vivo. These biochemical data were then correlated with pathophysiologic changes of the developing injury. We also sought to determine the sources of enzymes and oxidants released in the pulmonary tissues. The capacity to measure the generation of oxidants, proteolytic enzymes, and other potential mediators of inflammation is essential for the proper evaluation of therapeutic agents presumed to inhibit components of these systems.

\section{Methods}

Materials. Glucose oxidase (from Aspergillus niger, type V), catalase (from bovine liver), bovine serum albumin (essentially globulin-free), 3-amino-1,2,4 triazole, and reduced and oxidized glutathione were obtained from Sigma Chemical Co. (St. Louis, MO). Glucose oxidase and catalase were diluted in phosphate-buffered saline (final pH 6.6) and kept on ice. To heat inactivate them, they were kept at $70^{\circ}$ for $50 \mathrm{~min}$.

Bovine serum albumin (BSA) was radioiodinated $\left({ }^{125} \mathrm{NaI}, 100 \mathrm{mCi} /\right.$ $\mathrm{ml}$, Amersham Corp., Arlington Heights, IL) according to the chloramine T method (14). Washed rabbit erythrocytes in an equal volume of phosphate-buffered saline (PBS) were incubated with $25 \mu \mathrm{Ci}$ of ${ }^{51} \mathrm{Cr} / \mathrm{ml}$ of packed cells $\left({ }^{51} \mathrm{Cr}, 1 \mathrm{mCi} / \mathrm{ml}\right.$, Amersham Corp.) for $25 \mathrm{~min}$ at room temperature, washed twice with PBS, and resuspended in rabbit plasma.

FNLP (Vega Biochemicals, Tucson, AZ) was dissolved in $30 \mu \mathrm{l}$ of dimethyl sulfoxide/mg and diluted to $100 \mu \mathrm{g} / \mathrm{ml}$ in saline. PMA (Midland Corp., Brewster, NJ) was dissolved in $100 \mu \mathrm{l}$ of dimethyl sulfoxide/mg and kept in the dark at $-70^{\circ} \mathrm{C}$. Just before use aliquots were thawed and diluted to $20 \mu \mathrm{g} / \mathrm{ml}$ in saline. Nitrogen mustard (Mustargen) was obtained from Merck Sharp \& Dohme (West Point, PA). Rabbit catalase and goat anti-rabbit catalase were prepared as described below.

Animals and methods of inducing and measuring pulmonary inflammatory injury. 2.0-2.5-kg New Zealand white rabbits were anes- thesized with $30 \mathrm{mg} / \mathrm{kg}$ of pentobarbital (Diabutol) and tracheostomized, and the inciting agent was injected in a volume of $6 \mathrm{ml}$ in PBS (pH 7.4) containing $0.005 \%$ Evans blue and $0.5 \%$ BSA into the airways via a tracheal catheter. To induce pulmonary inflammatory injury, different inciting agents were used. Leukocytic stimuli and doses used were: FNLP $(200 \mu \mathrm{g} / \mathrm{kg})$, given twice, $5 \mathrm{~h}$ apart, and PMA $(40 \mu \mathrm{g} / \mathrm{kg})$. PMA was infused intravenously as well at a concentration of $80 \mu \mathrm{g} / \mathrm{kg}$ to induce pulmonary inflammation through the vascular route. To produce directly $\mathrm{H}_{2} \mathrm{O}_{2}$ in situ, glucose oxidase ( 150 or $250 \mathrm{U}$ in $3 \mathrm{ml} \mathrm{PBS}, \mathrm{pH} 6.6$ ) was instilled intrabronchially, immediately followed by the same volume of substrate ( $20 \mathrm{mg}$ glucose). Control animals received the same volume of PBS without stimulus. Using Evans blue as a marker, we generally observed a patchy distribution of the reagent in both lungs.

The experiment was terminated when the inflammatory reaction in the lung had developed as found in preliminary experiments: FNLP, 6 $\mathrm{h}$; PMA, $4 \mathrm{~h}$; and GO/G, $2 \mathrm{~h}$.

Pulmonary edema was measured by the leakage of ${ }^{125}$ I-BSA from the circulation into the lung tissues. For this purpose $8 \mu \mathrm{Ci}$ of ${ }^{125} \mathrm{I}$-BSA was injected intravenously $1 \mathrm{~h}$ before killing to allow transudation to occur into the inflamed lung tissues. To correct for intravascular ${ }^{125}$ I-BSA, $\sim 35 \mu \mathrm{Ci}$ of ${ }^{51} \mathrm{Cr}$-labeled rabbit erythrocytes were injected intravenously along with $800 \mathrm{U}$ of heparin (Gibco Laboratories, Chagrin Falls, $\mathrm{OH}$ ) $1 \mathrm{~min}$ before killing with $100 \mathrm{mg}$ pentobarbital. Blood was taken to correct for the ${ }^{125}$ I-BSA in the pulmonary circulation. Although we originally perfused the pulmonary vessels with saline for $10 \mathrm{~min}$ under $20 \mathrm{cmH}_{2} \mathrm{O}$ pressure, the amount of transudation of ${ }^{125} \mathrm{I}-\mathrm{BSA}$ into the lung tissue that we measured and corrected for blood content was not affected by saline perfusion, so we then discontinued this process except when necessary for other purposes. At autopsy, the trachea was clamped to avoid blood contamination and the lungs and heart were rapidly removed.

Preparation of samples. Within $2 \mathrm{~min}$ of killing $3 \mathrm{ml}$ of saline containing $\sim 500 \mathrm{cpm} / \mathrm{ml}^{131} \mathrm{I}-\mathrm{BSA}$ as a marker of dilution was instilled into one lower lobe through a fine cannula which was left in place for $10 \mathrm{~min}$, at which time another $1 \mathrm{ml}$ of saline plus ${ }^{131} \mathrm{I}$-BSA was added. Fluid in this lobe was gently aspirated. This procedure yielded more reproducible results than were obtained with immediate withdrawal of the lavage. Inasmuch as lavages did not contain any ${ }^{51} \mathrm{Cr}$ radioactivity, ${ }^{131}$ I-BSA could be used as a marker of dilution. The amount of ${ }^{131} \mathrm{I}$ BSA used was too small to interfere with the ${ }^{51} \mathrm{Cr}$ counts in the whole lungs.

Gross and microscopic examination revealed that as little as $0.5 \mathrm{ml}$ of $2 \%$ gelatin containing colloidal carbon administered in the mainstem bronchus of an excised lung reached the alveolar space within $5 \mathrm{~s}$. This suggested that lavage fluids were in contact with the terminal bronchioles and alveolar spaces. The possibility must nevertheless be considered that variation in protein binding to pulmonary structures may exist, and that differences in the efficiency of recovery of different enzymes cannot be excluded.

The recovered lavage fluid was centrifuged at $3,000 \mathrm{~g}$ for $10 \mathrm{~s}$, and the cell-free supernatant snap-frozen. Erythrocytes in the cell pellet were lysed with $1 \mathrm{ml}$ of $0.87 \% \mathrm{NH}_{4} \mathrm{Cl}$ for 5 min. After centrifugation and resuspension in $0.5 \mathrm{ml}$ of PBS, the cells ( $>85 \%$ macrophages) were counted and lysed by freeze-thawing three times in $\mathrm{H}_{2} \mathrm{O}$.

After taking small sections for light microscopy through the midportion of each lower lobe, lungs were rapidly frozen and radioactivity was determined by counting the whole lungs. After lyophilization the lungs were weighed and powdered in liquid $\mathrm{N}_{2}$, and aliquots were lysed in $1 \%$ Triton X-100 and $1 \mathrm{mM}$ EDTA $(50 \mathrm{mg}$ dry $\mathrm{wt} / \mathrm{ml})$. The supernatant after centrifugation was immediately analyzed for total glutathione. 
Neutrophil depletion. Rabbits were depleted of neutrophils with an intravenous injection of $1.75 \mathrm{mg} / \mathrm{kg}$ nitrogen mustard (Mustargen) 72 $h$ before the experiment. Immediately before the experiment a blood sample was taken and neutrophils were counted in a hemocytometer. Neutrophil counts were always $<300 / \mathrm{mm}^{3}$.

Enzyme analysis. The lavage fluid was assayed for the presence of leukocytic enzymes. Because rabbit neutrophils contain principally acid cathepsins, acid protease in the lavage fluid was measured at $\mathrm{pH} 3.0$ with denatured hemoglobin as substrate. At this $\mathrm{pH},>85 \%$ of both cathepsins $\mathrm{D}$ and $\mathrm{E}$ are measured. Cleavage fragments, not precipitated by TCA ( $5 \%$ final concentration), were measured in a Folin assay (15) and compared with cleavage of denatured hemoglobin produced by $10^{6}$ lysed rabbit polymorphonuclear neutrophils (PMN). Myeloperoxidase was determined spectrophotometrically in the presence of $10 \mathrm{mM} \mathrm{H}_{2} \mathrm{O}_{2}$ and $o^{\prime}$-dianisidine as described for horseradish peroxidase (16).

Oxidant generation during the development of pulmonary inflammation. To demonstrate oxidant activity in vivo, we employed the reaction in which catalase in its active form as catalase- $\mathrm{H}_{2} \mathrm{O}_{2}$ complex (compound I) is irreversibly inactivated by 3-amino, 1,2,4 triazole (AT). AT injected intraperitoneally persists for 2-6 $\mathrm{h}$ (17), and inactivation of catalase by AT reflects $\mathrm{H}_{2} \mathrm{O}_{2}$ generation in vivo $(18,19)$. In our experimental animals $1 \mathrm{~g} / \mathrm{kg}$ AT was injected intraperitoneally $1 \mathrm{~h}$ before sacrifice, and catalase activity in the fluid-phase BAL was measured photometrically by the disappearance of $10 \mathrm{mM} \mathrm{H}_{2} \mathrm{O}_{2}$ at $240 \mathrm{~nm}(20)$. Total catalase protein content of the lavage fluid was determined by the quantitative enzyme-linked immunosorbent assay (ELISA) technique.

Preparation of rabbit catalase and ELISA assay for catalase. Rabbit catalase was prepared by the method described elsewhere for human catalase (Revak, S. D., C. Rice, I. U. Schraufstätter, W. Halsey, B. Bohl, and C. G. Cochrane, manuscript submitted for publication). In short, a lysate of washed fresh rabbit erythrocytes was passed over a DEAESephacel column (Pharmacia Fine Chemicals, Piscataway, NJ). The 50$70 \%$ ammonium sulfate fraction was applied to a column of sulphopropylSephadex (Pharmacia Fine Chemicals) (21). The catalase pool showed $>95 \%$ homogeneity on reduced sodium dodecyl sulfate-polyacrylamide gels.
Goat antiserum was prepared by weekly multiple intradermal injections of $100 \mu \mathrm{g}$ of purified catalase in complete Freund's adjuvant (Difco Laboratories, Detroit, MI). Antibody showed a single coalescent line in double immunodiffusion agar with purified catalase or erythrocyte lysates.

Total catalase content was determined by ELISA technique essentially as described (Revak, S. D., C. Rice, I. U. Schraufstätter, W. Halsey, B. Bohl, and C. G. Cochrane, manuscript submitted for publication). 20 $\mu \mathrm{g}$ of immunopurified goat anti-rabbit $\mathrm{F}\left(\mathrm{ab}^{\prime}\right)_{2}$ were placed into microtiter wells. After incubation and washing, standards containing 1-20 ng of catalase or lavage fluids were added. Next, $1 \mu \mathrm{g}$ of immunopurified goat anti-rabbit catalase was added, followed by $3 \mu \mathrm{g}$ rabbit antibody to goat immunoglobulin Fc. This step was necessary, because the goat antibody did not bind protein A. Finally, glucose oxidase complexed to protein A was added, and the color formation in the presence of $o$-phenylene diamine, horseradish peroxidase, and glucose, stopped with $\mathrm{H}_{2} \mathrm{SO}_{4}$, was read at $492 \mathrm{~nm}$. A linear relationship existed between the concentration of rabbit catalase or sample dilutions and the absorbance reading.

Determination of total glutathione. The sum of reduced and oxidized glutathione was determined by following the disappearance of reduced nicotinamide adenine dinucleotide phosphate at $340 \mathrm{~nm}$ in the presence of glutathione reductase and 5,5'-dithiobis-(2-nitrobenzoic acid) (22).

\section{Results}

Lung injury produced by $G O / G$. The instillation of two different doses of glucose oxidase ( 150 and 250 units) plus $20 \mathrm{mg}$ glucose induced acute lung injury by $2 \mathrm{~h}$, as evidenced by a $>10$-fold increase in vascular permeability in the lungs as compared with the negative control (Table I). Acid protease and myeloperoxidase levels in the BAL fluid increased concomitantly. A fall in arterial $\mathrm{PO}_{2}$ from an average of 75 to $55 \mathrm{mmHg}$ accompanied the development of the injury. Histologically, we observed severe edema formation in the interstitial and alveolar spaces with few neutrophils present (Fig. 1).

Table I. GO/G-Induced Pulmonary Edema and Release of Leukocytic Enzymes in the Lungs of Rabbits

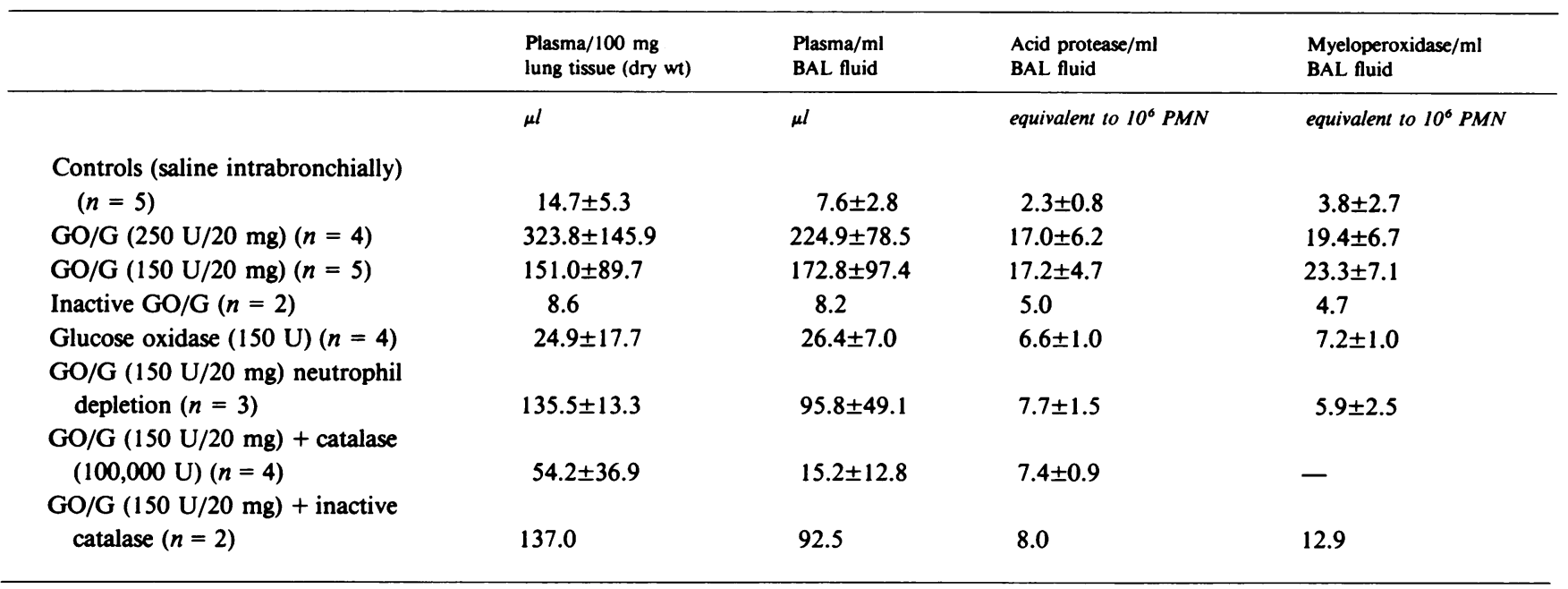

GO/G was given intrabronchially in a volume of $6 \mathrm{ml} 2 \mathrm{~h}$ before killing. Means \pm SEM. 


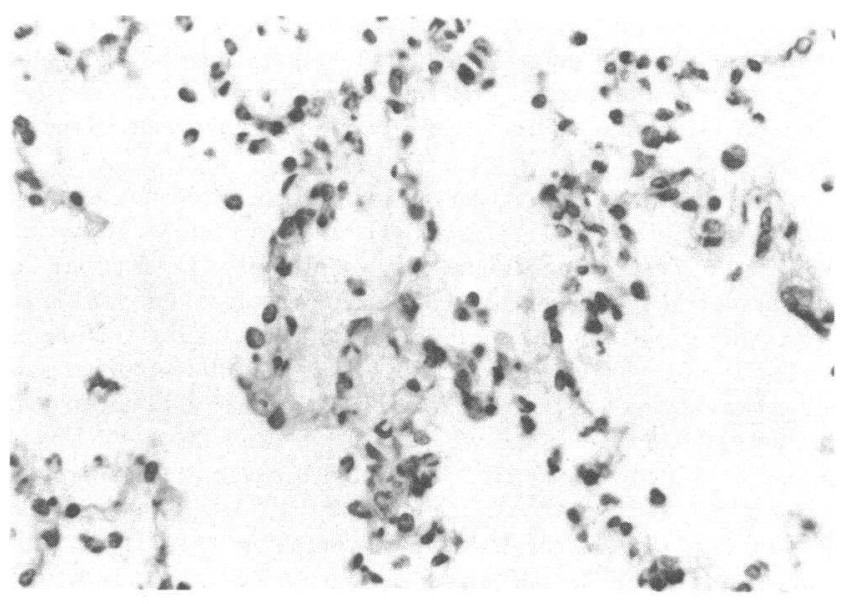

Figure 1. Light microscopy photograph of rabbit lung $2 \mathrm{~h}$ after intrabronchial instillation of $\mathrm{GO} / \mathrm{G}$. For description, see text.

Heat inactivation $\left(50 \mathrm{~min}\right.$ at $\left.70^{\circ} \mathrm{C}\right)$ of the glucose oxidase blocked its ability to induce edema. Glucose oxidase without glucose induced mild edema formation. Presumably the injury was induced by small amounts of glucose physiologically present.

After neutrophil depletion a small decrease in edema formation was noticed. While myeloperoxidase levels dropped to almost control values, the amount of acid protease was diminished only by about $50 \%$, suggesting release from alveolar macrophages. Histologic analysis showed a nearly complete absence of neutrophils in sections of the lung.

Intrabronchial instillation of $100,000 \mathrm{U}$ of bovine catalase at the time of induction of injury inhibited the GO/G-mediated injury considerably. The amount of intrabronchial edema was reduced by $90 \%$. High concentrations of catalase activity were measured in the BAL fluid at the termination of the experiment. Heat-inactivated catalase did not show any inhibitory effect.

A 10 -fold increase in the dose of catalase failed to show any greater beneficial effect.

Lung injury produced by FNLP. To determine the persistence of small, leukocyte-stimulating peptides in lung tissues, a tracer amount of ${ }^{125} \mathrm{I}-\mathrm{N}$-formyl-nleu-leu-phe-nleu-tyr-lys was combined with FNLP $(200 \mu \mathrm{g} / \mathrm{kg})$ and instilled intrabronchially. Complete recovery in the lung tissue was achieved immediately after instillation, whereas at $4 \mathrm{~h}$, only $30 \%$ of the initial amount of hexapeptide could be found in the lungs.

A single dose of FNLP $(200 \mu \mathrm{g} / \mathrm{kg})$ given intrabronchially produced a decrease in circulating neutrophils to $\sim 30 \%$ of initial values with a return to normal levels after about $2 \mathrm{~h}$. Histologically a moderate accumulation of neutrophils in the pulmonary tissues was observed at $1 \mathrm{~h}$, as observed with the light microscope, and levels of neutrophil enzymes in the lavage fluid were slightly, but not significantly increased: acid protease (units of activity per milliliter of BAL fluid) rose from values equivalent to protease contained in $2.3 \times 10^{6} \mathrm{PMN}$ in controls to 7.6 $\times 10^{6} 1 \mathrm{~h}$ after FNLP treatment. But edema formation or oxidant production (see below) were only transient (Fig. 2A).

To induce greater generation and release of injurious constituents of leukocytes, FNLP was instilled at 0 and $5 \mathrm{~h}$. In this manner, neutrophils accumulating in the lung after the first injection of chemotactic peptide could presumably be stimulated by the second instillation of the same dose of FNLP. In these animals permeability and enzyme levels increased two- to threefold over control values: plasma transudation into the lung tissue increased from 14.7 to $36.8 \mu \mathrm{l} / 100 \mathrm{mg}$ of lung tissue, and from 7.6 to $15.4 \mu \mathrm{l} / \mathrm{ml}$ in the lavage fluid (Table II). Levels of acid protease in $1 \mathrm{ml}$ BAL fluid rose from 2.3 to 7.2 equivalents of $10^{6}$ lysed PMN; myeloperoxidase levels increased concomitantly. No protease activity determined with the same substrates as at acid $\mathrm{pH}$ could be detected in BAL fluids at $\mathrm{pH}$ of 7.0. Neutrophil depletion completely inhibited the injury (see Table II).

At $6 \mathrm{~h}$, a diffuse inflammatory reaction was observed histologically with moderate edema formation, neutrophils present in the septal tissues and alveolar spaces. Accumulation of neutrophils was dominant at $6 \mathrm{~h}$ (see Fig. 3). By $24 \mathrm{~h}$, few neutrophils were observed, but large numbers of macrophages were observed in the septae and alveolar spaces. After neutrophil depletion cellular infiltration was not observed at $6 \mathrm{~h}$ (the only time of examination).

Lung injury produced by PMA. PMA was either instilled intrabronchially at a concentration of $40 \mu \mathrm{g} / \mathrm{kg}$ or injected slowly

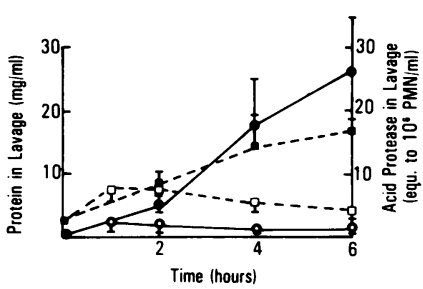

Figure 2. Time course of different parameters of pulmonary injury after a single intrabronchial instillation of FNLP

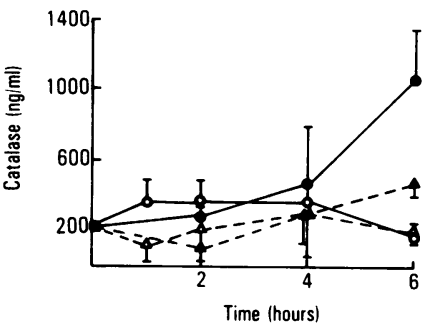
(400 $\mu \mathrm{g} / \mathrm{kg}$ ) (open symbols) or PMA (40 $\mu \mathrm{g} / \mathrm{kg}$ ) (closed symbols). ( $A$ ) Protein and protease content in BAL fluid. (一० -), (-•-), protein; (-- - - - - ), (-- - - - - ), and protease. $(B)$ Total catalase content and catalase activity in the BAL fluid in the presence of AT $(1 \mathrm{~g} / \mathrm{kg})$ given i.p. $1 \mathrm{~h}$ before killing in the case of

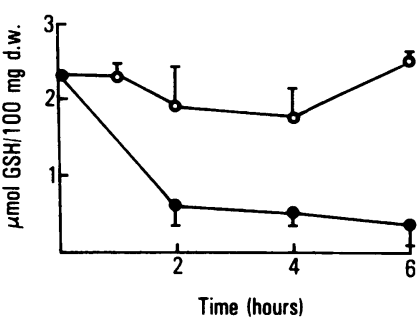

FNLP, and $2 \mathrm{~h}$ before killing in the rabbits receiving PMA. (-o - ), (- - - ), total catalase, $(---\Delta---),(---\Delta--)$, active catalase. $(C)$ Total glutathione content in whole lung tissue after perfusion. d.w., dry weight. 
Table II. Edema Formation and Release of Leukocytic Enzymes in the Lungs of Normal and Neutrophil-Depleted Rabbits Induced by FNLP and PMA

\begin{tabular}{|c|c|c|c|c|}
\hline & $\begin{array}{l}\text { Edema in lung } \\
\text { plasma/100 } \\
\text { mg lung } \\
\text { tissue (dry wt) }\end{array}$ & $\begin{array}{l}\text { Plasma } \\
\text { transudation } \\
\text { into BAL } \\
\text { fluid }\end{array}$ & $\begin{array}{l}\text { Acid protease } / \mathrm{ml} \\
\text { BAL fluid }\end{array}$ & $\begin{array}{l}\text { Myeloperoxidase/ml } \\
\text { BAL fluid }\end{array}$ \\
\hline & $\mu l$ & $\mu l / m l$ & equivalent to $10^{6} P M N$ & equivalent to $10^{6} \mathrm{PMN}$ \\
\hline Controls (PBS i.b.) $(n=5)$ & $14.7 \pm 5.3$ & $7.6 \pm 2.8$ & $2.3 \pm 0.8$ & $3.8 \pm 2.6$ \\
\hline FNLP $2 \times$ i.b. $(n=6)$ & $36.8 \pm 11.3$ & $15.4 \pm 7.9$ & $7.2 \pm 1.7$ & $7.0 \pm 2.4$ \\
\hline $\begin{array}{l}\text { FNLP } 2 \times \text { neutrophil } \\
\text { depletion }(n=6)\end{array}$ & $13.4 \pm 8.9$ & $4.8 \pm 2.4$ & $2.7 \pm 0.6$ & $2.6 \pm 0.1$ \\
\hline PMA i.b. $(n=9)$ & $58.8 \pm 16.2$ & $43.0 \pm 25.0$ & $14.5 \pm 4.8$ & $15.7 \pm 9.6$ \\
\hline $\begin{array}{l}\text { PMA i.b. neutrophil } \\
\text { depletion }(n=4)\end{array}$ & $19.0 \pm 8.3$ & $9.5 \pm 3.0$ & $4.1 \pm 0.8$ & $7.0 \pm 1.7$ \\
\hline Controls (saline i.v.) $(n=3)$ & $4.7 \pm 2.8$ & $6.2 \pm 2.5$ & $1.7 \pm 0.3$ & $<2.2$ \\
\hline PMA i.v. $(n=4)$ & $44.7 \pm 20.5$ & $55.0 \pm 8.6$ & $14.5 \pm 1.6$ & $17.9 \pm 11.1$ \\
\hline $\begin{array}{l}\text { PMA i.v. neutrophil } \\
\text { depletion }(n=3)\end{array}$ & $4.3 \pm 3.2$ & $8.4 \pm 2.8$ & $2.5 \pm 0.4$ & $<2.2$ \\
\hline
\end{tabular}

FNLP $(200 \mu \mathrm{g} / \mathrm{kg})$ was given twice at 0 and $5 \mathrm{~h}$, and animals were killed at $6 \mathrm{~h}$. PMA (40 $\mu \mathrm{g} / \mathrm{kg}$ i.b. or $80 \mu \mathrm{g} / \mathrm{kg}$ i.v. $)$ was administered once and rabbits were killed $4 \mathrm{~h}$ later. i.b., intrabronchially.

(over a period of $1 \mathrm{~min}$ ) intravenously at $80 \mu \mathrm{g} / \mathrm{kg}$. These two different methods of application initiated similar inflammatory responses (Table II). In both cases plasma transudation into the lung tissue and lavage fluid increased four- to fivefold over control levels. Acid protease and myeloperoxidase concentrations in the lavage fluid increased by about the same amount.

Neutrophil depletion completely inhibited the transudation of protein into the lungs if PMA was given intravenously. With intrabronchial administration lung injury decreased significantly, but could not be completely abolished.

Histologically, thickening of the septae and accumulation

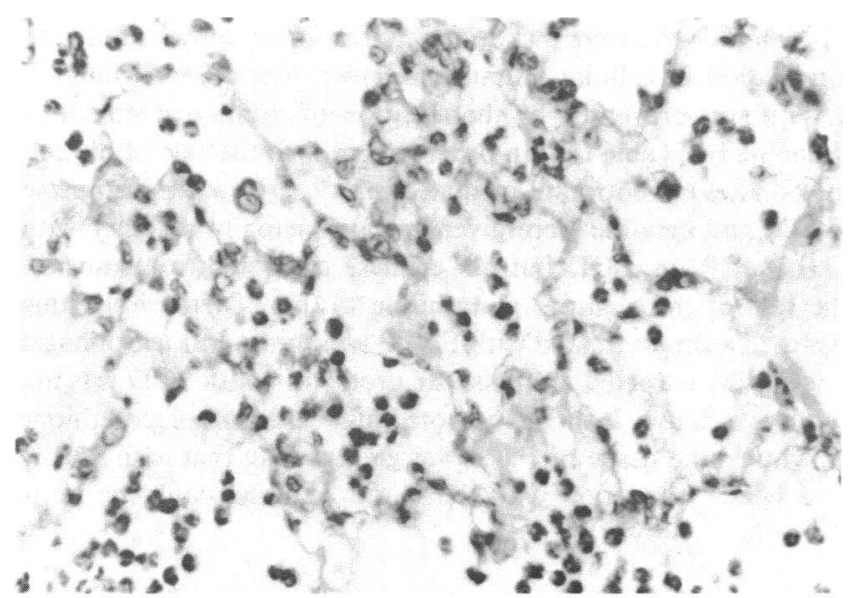

Figure 3. Light microscopy photograph of rabbit lung $1 \mathrm{~h}$ after a second instillation of FNLP $5 \mathrm{~h}$ after the first. For description, see text. of neutrophils mostly within vessels was noticed as early as 2 $h$ after intrabronchial instillation of PMA. At this time, there was little alveolar edema. At $4 \mathrm{~h}$, large numbers of neutrophils had passed into the alveolar space accompanied by marked edema and occasional deposits of fibrin and extravasation of erythrocytes. At $6 \mathrm{~h}$, this hemorrhagic component became more dominant. Occasionally a platelet thrombus surrounded by neutrophils could be seen in blood vessels. PMA administered intravenously induced a more diffuse, but otherwise very similar inflammatory reaction.

Oxidant generation during the development of pulmonary inflammation. To demonstrate the production of $\mathrm{H}_{2} \mathrm{O}_{2}$ in vivo we employed the biochemical reaction in which catalase in its active form as catalase- $\mathrm{H}_{2} \mathrm{O}_{2}$ complex (compound $\mathrm{I}$ ) is irreversibly inhibited by AT. Catalase in the absence of $\mathrm{H}_{2} \mathrm{O}_{2}$ is not inactivated by AT. Rabbits with pulmonary inflammation received $1 \mathrm{~g} / \mathrm{kg}$ of AT i.p. $1 \mathrm{~h}$ before sacrifice and the extracellular catalase in the BAL fluid was measured for activity and for catalase protein concentration (see Methods).

AT in control animals receiving saline intrabronchially caused a small decrease in specific catalase activity, probably due to nonspecific stimulation of neutrophils or resident macrophages.

In 22 rabbits receiving GO/G or a double injection of FNLP, AT caused a decrease of catalase specific activity in the lavage fluid of $70-90 \%$ (Table III). This represented indirect evidence of in vivo $\mathrm{H}_{2} \mathrm{O}_{2}$ formation in the FNLP-induced pulmonary inflammation. Neutrophil depletion had no influence on inhibition of catalase by AT in GO/G animals, but in animals receiving FNLP, neutrophil depletion prevented most of the inhibition of catalase by AT (Table III). This suggested that at 
Table III. Generation of $\mathrm{H}_{2} \mathrm{O}_{2}$ In Vivo as Measured by the Inhibition of Catalase in the Presence of $A T$

\begin{tabular}{|c|c|c|c|c|c|}
\hline Inciting agent & Time & AT & $\begin{array}{l}\text { Catalase } \\
\text { activity }\end{array}$ & $\begin{array}{l}\text { Total } \\
\text { catalase }\end{array}$ & $\begin{array}{l}\text { Specific } \\
\text { activity }\end{array}$ \\
\hline & $h$ & & $\begin{array}{l}\mu g / m l B A L \\
\text { fluid }\end{array}$ & $\begin{array}{l}\mu g / m l B A L \\
\text { fluid }\end{array}$ & \\
\hline Saline i.b. & 6 & - & $234 \pm 22$ & $218 \pm 33$ & 1.07 \\
\hline Saline i.b. & 6 & + & 184 & 256 & 0.72 \\
\hline $\mathrm{GO} / \mathrm{G}$ & 2 & - & $475 \pm 63$ & $508 \pm 98$ & 0.94 \\
\hline GO/G & 2 & + & $67 \pm 54$ & $447 \pm 62$ & 0.15 \\
\hline \multicolumn{6}{|c|}{ GO/G neutrophil } \\
\hline depletion & 2 & - & $363 \pm 103$ & 370 & 0.98 \\
\hline \multicolumn{6}{|c|}{ GO/G neutrophil } \\
\hline depletion & 2 & + & $31 \pm 22$ & 388 & 0.08 \\
\hline FNLP & 6 & - & $367 \pm 125$ & $346 \pm 109$ & 1.06 \\
\hline FNLP & 6 & + & $42 \pm 18$ & $188 \pm 4$ & 0.22 \\
\hline \multicolumn{6}{|c|}{ FNLP neutrophil } \\
\hline depletion & 6 & - & $265 \pm 94$ & $244 \pm 91$ & 1.08 \\
\hline \multicolumn{6}{|c|}{ FNLP neutrophil } \\
\hline depletion & 6 & + & $227 \pm 73$ & $251 \pm 139$ & 0.90 \\
\hline PMA i.b. & 2 & - & $300 \pm 61$ & $288 \pm 73$ & 1.04 \\
\hline PMA i.b. & 2 & + & $110 \pm 69$ & $293 \pm 69$ & 0.38 \\
\hline PMA i.b. & 4 & - & $490 \pm 310$ & $500 \pm 217$ & 0.98 \\
\hline PMA i.b. & 4 & + & $324 \pm 178$ & $577 \pm 108$ & 0.56 \\
\hline PMA i.b. & 6 & - & $1060 \pm 169$ & $1115 \pm 155$ & 0.96 \\
\hline PMA i.b. & 6 & + & $489 \pm 78$ & $913 \pm 181$ & 0.53 \\
\hline Saline i.v. & 4 & + & 84 & 90 & 0.93 \\
\hline PMA i.v. & 2 & + & $109 \pm 58$ & $153 \pm 37$ & 0.75 \\
\hline PMA i.v. & 4 & + & $220 \pm 142$ & $248 \pm 138$ & 0.88 \\
\hline PMA i.v. & 6 & + & 178 & 183 & 0.97 \\
\hline
\end{tabular}

i.b., intrabronchially.

Inhibition of catalase by AT $(1 \mathrm{~g} / \mathrm{kg})$ in the presence of $\mathrm{H}_{2} \mathrm{O}_{2}$ in rabbit lavage fluid. Inciting agents and concentrations used are: $\mathrm{GO} / \mathrm{G}$ $(150 \mathrm{U} / 20 \mathrm{mg})$, FNLP twice at 0 and $5 \mathrm{~h}(200 \mu \mathrm{g} / \mathrm{kg})$, PMA i.b. (40 $\mu \mathrm{g} / \mathrm{kg})$ and i.v. $(80 \mu \mathrm{g} / \mathrm{kg})$. AT was given intraperitoneally $1 \mathrm{~h}$ before killing. Rabbit erythrocyte catalase $(47,600 \mathrm{U} / \mathrm{mg}$ protein) was used as standard. Values are means \pm SEM in four to seven animals except in those cases where SEM values are not shown.

this time, neutrophils were responsible, either directly or indirectly, for the majority of the $\mathrm{H}_{2} \mathrm{O}_{2}$ generated. Catalase in the washed cell pellet ( $>85 \%$ macrophages) obtained by centrifugation of BAL fluid, was inhibited by AT in FNLP-treated rabbits $(488 \pm 197 \mathrm{ng} / \mathrm{mg}$ of protein, $n=3)$ compared with $3,500 \pm 982$ $\mathrm{ng} / \mathrm{mg}$ of protein in control animals and $2,800 \mathrm{ng} / \mathrm{mg}$ of protein $(n=2)$ in controls which received AT. This inhibition could be completely reversed by neutrophil depletion $(3,083 \pm 1,128$ $\mathrm{ng} / \mathrm{mg}$ protein, $n=5$ ). Neutrophil depletion had no influence on the inactivation of catalase in macrophages by AT injected at the time of induction of injury in rabbits given $G O / G$ in which $\mathrm{H}_{2} \mathrm{O}_{2}$ was presumably produced by the enzyme irrespective of cells.

With a single intrabronchial instillation of FNLP, catalase inactivation in the presence of AT was observed during the first hour (sp act $=0.30$ ) (Fig. 1). At $4 \mathrm{~h}$, however, the specific activity of catalase rose to 0.75 , suggesting that $\mathrm{H}_{2} \mathrm{O}_{2}$ was generated only for a short period of time.

In animals receiving PMA intrabronchial a steady increase in catalase content was observed during 6-h period when it amounted to about fourfold the concentration seen in control animals. In the presence of AT, catalase activity between 2 and $6 \mathrm{~h}$ was inhibited, although in terms of percent of total catalase present, to a lesser extent than in FNLP-treated rabbits. This may result from the larger total extracellular content of catalase in PMA-treated rabbits. Little inhibition of catalase by AT was seen after intravenous administration of PMA.

Loss of intracellular glutathione. A second approach to the detection of the presence of oxidants generated in situ was to measure a diminution in the intracellular defenses to oxidants. Measurements of total intracellular glutathione were used as an indication of the participation of the glutathione oxidation-reduction cycle in antioxidant reactions. Total glutathione was measured in whole lung tissue after perfusion and, in washed alveolar macrophages. Glutathione levels determined in our standard tissue preparation were not different from values obtained with immediate deproteination by acid treatment.

With intrabronchially administered PMA, glutathione levels dropped from 2.3 to $0.67 \mu \mathrm{mol}$ glutathione equivalent $/ 100 \mathrm{mg}$ dry wt within the first $2 \mathrm{~h}$ and further decreased to $<15 \%$ of the control values within the next $4 \mathrm{~h}$. Similar results were seen after intravenous administration, although diminution of glutathione in alveolar macrophages required longer times when PMA was given intravenously (Table IV). After instillation of FNLP, a diminution of glutathione was also observed.

An almost complete protection from loss of cellular glutathione was observed in animals which were neutrophil depleted.

When $\mathrm{GO} / \mathrm{G}$ were instilled intrabronchially only a moderate diminution in cellular glutathione levels was observed after 2 h. This was prevented by the addition of catalase given intrabronchially. (Table IV). In order to establish the role of oxygen metabolites in neutrophil-mediated injury, superoxide dismutase (SOD) and catalase were given intrabronchially together with FNLP or PMA. SOD but not catalase protected from most of the loss of intracellular glutathione (Table V) in whole lung tissue of animals treated with FNLP two times. In macrophages and in PMA-treated animals, the protection with SOD was not quite as effective. It should be noted that depletion of glutathione in whole lung tissue by PMA was greater than that with FNLP, and hence protection with SOD and catalase would be more difficult.

\section{Discussion}

The present study provides evidence for the presence of oxidants and proteases, generated in situ during the development of in- 
Table IV. Effect of Pulmonary Inflammation on Total Glutathione Levels in Whole Lung Tissue and Alveolar Macrophages

\begin{tabular}{|c|c|c|c|c|}
\hline Inciting agent & & Time & $\begin{array}{l}\text { Glutathione in } \\
\text { whole lung } \\
\text { tissue }\end{array}$ & $\begin{array}{l}\text { Glutathione } \\
\text { in alveolar } \\
\text { macrophages }\end{array}$ \\
\hline & $n$ & $h$ & $\begin{array}{l}\text { umol GSH } \\
\text { equivalent/100 } \\
\text { mg dry wt }\end{array}$ & $\begin{array}{l}\text { nmol GSH } \\
\text { equivalent/mg } \\
\text { protein }\end{array}$ \\
\hline Saline & 3 & 4 & $2.30 \pm 0.11$ & $34.8 \pm 1.4$ \\
\hline PMA i.b. & 5 & 2 & $0.67 \pm 0.25$ & $8.8 \pm 1.5$ \\
\hline PMA i.b. & 5 & 4 & $0.54 \pm 0.17$ & ND \\
\hline PMA i.b. & 6 & 6 & $0.39 \pm 0.27$ & $4.4 \pm 2.2$ \\
\hline \multicolumn{4}{|l|}{ PMA i.b. neutrophil } & $36.2 \pm 9.5$ \\
\hline PMA i.v. & 4 & 2 & $1.62 \pm 0.36$ & $28.2 \pm 14.5$ \\
\hline PMA i.v. & 4 & 4 & $0.48 \pm 0.13$ & $25.3 \pm 9.3$ \\
\hline PMA i.v. & 4 & 6 & $0.26 \pm 0.02$ & $14.6 \pm 8.1$ \\
\hline $2 \times$ FNLP i.b. & 6 & 4 & $1.80 \pm 0.37$ & $18.1 \pm 6.2$ \\
\hline $2 \times$ FNLP i.b. & 5 & 6 & $1.34 \pm 0.31$ & $9.2 \pm 2.3$ \\
\hline \multicolumn{5}{|l|}{$2 \times$ FNLP neutrophil } \\
\hline depletion & 7 & 6 & $1.87 \pm 0.13$ & ND \\
\hline GO/G & 4 & 2 & $1.68 \pm 0.14$ & $22.5 \pm 7.8$ \\
\hline \multicolumn{5}{|l|}{$\mathrm{GO} / \mathrm{G}+100,000 \mathrm{U}$} \\
\hline catalase & 4 & 2 & $1.84 \pm 0.20$ & $34.6 \pm 6.6$ \\
\hline
\end{tabular}

i.b., intrabronchially; ND, not determined.

Conditions are the same as in Table III. Values are means \pm SEM.

flammatory injury of the lung in rabbits. The injury was induced by administration of the leukocytic stimuli, FNLP and PMA. The stimuli were given intrabronchially and intravenously.

The generation of oxidants in vivo. One of the major objectives of this study was to detect the presence of oxidants generated in the inflammatory site. We employed two means to accomplish this: the inactivation of catalase complexed with $\mathrm{H}_{2} \mathrm{O}_{2}$ by AT (see Methods) as a measure of $\mathrm{H}_{2} \mathrm{O}_{2}$ generation, and the depletion of the intracellular antioxidant, reduced glutathione (GSH). In a study of pulmonary inflammation in rhesus monkeys, to be reported separately, the oxidative inactivation of $\alpha_{1}$-PI has also been employed to indicate the generation of oxidants in vivo as it has been used in acute pulmonary inflammatory disease of human beings (4). Rabbit $\alpha_{1}$-PI is less susceptible to oxidation and could not be used as an indicator of oxidant formation in this species.

The inactivation of catalase by AT in the extracellular fluid in inflamed lungs of rabbits was measured by the loss of specific activity of the catalase (Table III). Several observations support the possibility that $\mathrm{H}_{2} \mathrm{O}_{2}$ was complexed with the catalase before inactivation by AT: extracellular catalase in control rabbits or rabbits depleted of neutrophils (the major contributor of oxi- dants) was not inactivated by $\mathrm{AT}$ in vivo; the generation of $\mathrm{H}_{2} \mathrm{O}_{2}$ by $\mathrm{GO} / \mathrm{G}$ in the lungs of normal rabbits brought about inactivation of catalase only in the presence of AT; and inactivation of catalase by proteases, oxidants, etc., did not occur because the specific activity of the catalase fell only in the inflamed lungs of rabbits given AT. Studies conducted in vitro established that catalase is inactivated by AT only when it is complexed with $\mathrm{H}_{2} \mathrm{O}_{2}(17,23)$.

Although there is a spectral change in catalase- $\mathrm{H}_{2} \mathrm{O}_{2}$ complex after inactivation with AT (24), this change has not been shown to be an absolute indication of the presence of $\mathrm{H}_{2} \mathrm{O}_{2}$ and its demonstration was therefore not attempted in this study. It should therefore be emphasized that these data are indirect in their support of the conclusion that $\mathrm{H}_{2} \mathrm{O}_{2}$ is generated during the development of pulmonary inflammation.

The predominant source of $\mathrm{H}_{2} \mathrm{O}_{2}$ appeared to be the neutrophil, although we cannot exclude the possibility that $\mathrm{H}_{2} \mathrm{O}_{2}$ was generated by other cells that might be stimulated by the neutrophils. Nevertheless, the generation of $\mathrm{H}_{2} \mathrm{O}_{2}$ in greatest part required the presence of neutrophils when either FNLP or PMA was used as stimulant.

Concentrations of catalase in the lavage fluid were higher in rabbits with inflammatory lung injury. The source of catalase was probably cells undergoing lytic injury during the development of inflammation, in that there was an apparent correlation of catalase levels and concentrations of lactate dehydrogenase in the BAL fluids. With PMA as stimulant, the extracellular catalase concentrations were considerably higher than when FNLP was used. The decrease in specific activity in the presence of AT was somewhat less than that when FNLP was

Table V. Effect of SOD and Catalase on Total Glutathione Levels in Whole Lung Tissue and Alveolar Macrophages

\begin{tabular}{cllll}
\hline & $\begin{array}{l}\text { Glutathione in } \\
\text { whole lung } \\
\text { tissue }\end{array}$ & & $\begin{array}{l}\text { Glutathione } \\
\text { in alveolar } \\
\text { macrophages }\end{array}$ \\
\hline & $\begin{array}{l}\text { umol GSH } \\
\text { equivalent/100 } \\
\text { mg dry } w t\end{array}$ & $n$ & $\begin{array}{l}\text { nmol GSH } \\
\text { equivalent/ } \\
\text { mg protein }\end{array}$ & $n$ \\
& $1.47 \pm 0.18$ & 8 & $9.1 \pm 1.8$ & 8 \\
$2 \times$ FNLP & $2.08 \pm 0.32$ & 8 & $27.3 \pm 1.4$ & 4 \\
$2 \times$ FNLP & $1.61 \pm 0.13$ & 4 & $13.0 \pm 2.5$ & 4 \\
$2 \times$ FND & $0.89 \pm 0.32$ & 9 & $8.8 \pm 1.5$ & 5 \\
+ catalase & $1.61 \pm 0.27$ & 7 & $25.9 \pm 13.2$ & 5 \\
PMA & $0.92 \pm 0.19$ & 4 & $10.3 \pm 2.3$ & 4 \\
PMA + SOD & & & & \\
PMA + catalase & & & & \\
\hline
\end{tabular}

FNLP $(200 \mu \mathrm{g} / \mathrm{kg})$ was administered twice at 0 and $5 \mathrm{~h}$ together with $140 \mu \mathrm{g}$ SOD or 100,000 U catalase (both from rabbit erythrocytes), and rabbits were killed at $6 \mathrm{~h}$. PMA (40 $\mu \mathrm{g} / \mathrm{kg}$ intrabronchially) was given together with $210 \mu \mathrm{g}$ SOD or $100,000 \mathrm{U}$ catalase, $2 \mathrm{~h}$ before killing. Values are means \pm SEM. 
used, perhaps reflecting an excessive amount of catalase relative to $\mathrm{H}_{2} \mathrm{O}_{2}$ generated, or catalase released from relatively large numbers of cells that only recently arrived at the site of inflammation. The minimal amount of catalase inhibition by AT in BAL fluid after intravenous administration of PMA might indicate that the $\mathrm{H}_{2} \mathrm{O}_{2}$ formed under these conditions did not reach the alveolar spaces to any large extent, or that less $\mathrm{H}_{2} \mathrm{O}_{2}$ is generated in intravenous stimulation with PMA.

The specific activity of catalase within alveolar cells (predominantly macrophages) and whole lung cells (washed lung tissue) also diminished in the presence of AT. As in the case of extracellular catalase, this was prevented by neutrophil depletion, suggesting that $\mathrm{O}_{2}^{-}$and/or $\mathrm{H}_{2} \mathrm{O}_{2}$, produced by the leukocytes diffused into target cells. The $\mathrm{O}_{2}^{-}$may undergo dismutation to form $\mathrm{H}_{2} \mathrm{O}_{2}$ intracellularly. In the presence of AT and intracellular $\mathrm{H}_{2} \mathrm{O}_{2}$, catalase could then undergo inactivation. $\mathrm{H}_{2} \mathrm{O}_{2}, \mathrm{O}_{2}^{-}$, and AT are all known to penetrate cell membranes freely $(25,26)$. It is possible that catalase was inhibited directly in macrophages, which produce their own oxidant during activation.

In the second method of detecting oxidants, measurements were made of intracellular glutathione in cells removed from the site of injury. Alveolar cells appearing in the BAL fluid, cells in washed whole lung preparations, and endothelial cells of the pulmonary vasculature all showed a fall in glutathione levels. Data support the concept that the fall in glutathione reflected the generation of oxidants: the depletion of neutrophils, the apparent source of oxidants when stimulated with FNLP or PMA, prevented in great part the fall in intracellular glutathione. Similarly, SOD prevented the diminution of glutathione. Glutathione levels within pulmonary cells have been shown to fall in oxygen toxicity (27). Furthermore, oxidized glutathione (GSSG) appears in the perfusate of isolated lungs or liver treated with hyperbaric oxygen (28) or hydroperoxides $(29,30)$. The rate of GSSG release is dependent on the amount of hydroperoxide utilized (31), and $\mathrm{H}_{2} \mathrm{O}_{2}$ generated intracellularly also gives rise to an increased GSSG release (30). Increased concentrations of intracellular GSSG can deleteriously affect the conformation or activity of thiol-containing proteins by disulfide interchange $(32,33)$ and are assumed to be removed from the cell by a translocase which has been characterized in erythrocytes (34). These data taken together make it probable that the substantial loss of total glutathione after leukocytic stimulation is caused by oxidation even though we did not determine the escape of GSSG in vivo. Intracellular GSSG levels were only marginally increased (data not shown). We cannot exclude the possibility that part of the loss of intracellular glutathione was due to formation of mixed disulfides between protein and glutathione which cannot be determined by our assay procedure.

The data suggest that oxidants are generated rapidly and consistantly during a 4-6-h period in the case of PMA-induced injury, and, with FNLP, in the first hour and again after the second stimulation with FNLP. The generation of oxidants by leukocytes stimulated with PMA is known to persist, whereas that with FNLP occurs as a burst during a 10-min period after stimulation. The detection of oxidants by the three methods noted above depends upon several factors which vary with each stimulus and with each assay. These factors include the number of infiltrating leukocytes, the local concentration of stimulant at the time of leukocytic accumulation, the duration of stimulation, the concentration of extracellular antioxidants, the rate of transudation of $\alpha_{1}$-PI in cases where its specific activity is measured, and, for the intracellular levels of glutathione, the rate of synthesis and either loss from the cell or metabolization within the cell. Studies in the whole animal do not allow definition of these variables, but measure net effects only.

In vivo the administration of xanthine oxidase-xanthine or GO/G caused severe pulmonary injury in rats (9) and in rabbits (Table I), which could be inhibited by SOD or catalase respectively. Intravenously administered catalase similarly inhibited edema formation induced by cobra venom factor (11). Nevertheless, whether oxidants are responsible, or whether catalase inhibits some other mediator of oxidant injury is unknown. Free oxygen radicals can induce various toxic effects, among them lipid peroxidation, protein denaturation, and DNA strand scission (26), but acute pathological changes on the cellular level are not well defined. $\mathrm{O}_{2}^{-}, \mathrm{HO}_{2}(35,36), \mathrm{H}_{2} \mathrm{O}_{2}(37,38), \mathrm{HOCl}$ in the presence of myeloperoxidase (39), $\mathrm{OH}^{\circ},(40,41), \mathrm{O}_{2}$, and RO' (42) have all been associated with oxidant-mediated injury with rather confusing conclusions even under in vitro conditions. $\mathrm{O}_{2}^{-}$itself is more of a reducing agent than an oxidant $\left(\mathrm{O}_{2}+3 \rightarrow \mathrm{O}_{\overline{2}}^{\overline{2}}, \mathrm{E}^{\circ}=-0.33 \mathrm{~V}\right)(43)$, but initiates the production of other more active oxygen species. $\mathrm{H}_{2} \mathrm{O}_{2}$ formed by the $\mathrm{GO} /$ $\mathrm{G}$ system - or its breakdown products-was sufficient to induce edema formation. In vitro experiments (unpublished data) have shown that the slow formation of $\mathrm{H}_{2} \mathrm{O}_{2}$ is sufficient to induce a loss of intracellular glutathione activity. Under in vivo conditions, however, SOD but not catalase could protect from a loss of intracellular glutathione, probably due either to its better accessibility on the vascular side and the interstitium because of its lower molecular weight, or to the fact that catalase does not scavenge low concentrations of $\mathrm{H}_{2} \mathrm{O}_{2}$ very efficiently.

The presence of proteases from leukocytes in situ was seen with either FNLP or PMA, used as inciting agents, and appeared in parallel with the presence of oxidants. There is little possibility that the protease activity in the BAL fluids-though not characterized by their molecular weight-derived from cells other than neutrophils or macrophages. The $\mathrm{pH}$ maximum for cleavage of hemoglobin was at pH 2.5, characteristic for neutrophil-derived cathepsin $\mathrm{E}$. In the present study no attempt was made to find evidence for the hydrolysis of basement membrane, but the appearance of erythrocytes in the BAL fluid after PMA injury might be an indication for the participation of proteases in the mediation of injury. In experimental glomerulitis large protein molecules and erythrocytes cleared the filtering glomerular basement membrane of rabbits with neutrophil mediated injury, and basement membrane degradation products could be demonstrated in the urine $(44,45)$. In isolated rabbit lungs perfused with elastase severe edema formation was ob- 
served (8), histologically characterized by injury of the endothelial cell lining and the vascular basement membrane. Injury induced by $\mathrm{GO} / \mathrm{G}$, presumed to be primarily caused by oxidant, showed high protease levels in the BAL fluids. This indicated that leukocytes were at least indirectly involved either due to direct stimulation of enzyme release by oxidants (46) and/or by the formation or release of PMN stimulatory substances or due to cell lysis. Depletion of neutrophils in these animals showed that the PMN was not of importance in the development of edema under these conditions. Removal of $\mathrm{H}_{2} \mathrm{O}_{2}$ by catalase led to diminution of protease activity in the BAL fluid in the GO/Gtreated animals. A relationship appears to exist between the presence of oxidants, generated in situ, and the appearance of extracellular proteases. It will be important to define the relationship between oxidants and proteases in the development of pulmonary injury when other agents are used to induce injury.

Although proteases and oxidants are both known to produce injury of tissue, the present data do not distinguish between them in evoking injury of the lung, nor do they preclude the possibility that other effectors play a role in development of the observed pulmonary inflammation. The marked inhibition of injury resulting from depletion of PMNs, however, suggests that these cells play a control role in the production of proteases, oxidants, or other mediators that may be important in the development of acute pulmonary injury in rabbits.

\section{Acknowledgments}

We thank Mr. Wayne Halsey for his excellent technical assistance, and Mrs. Monica Bartlett for preparation of the manuscript.

This work was supported by grants AI17354, HL16411, and P5023584 from the National Institutes of Health; by the Council for Tobacco Research; and by the Office of Naval Research.

\section{References}

1. McGuire, W. W., R. G. Spragg, A. B. Cohen, and C. G. Cochrane. 1982. Studies on the pathogenesis of the adult respiratory distress syndrome. J. Clin. Invest. 69:543-553.

2. Lee, C. T., A. M. Fein, M. Lippmann, H. Holtzman, P. Kimbel, and G. Weinbaum. 1981. Elastolytic activity in pulmonary lavage fluid from patients with adult respiratory distress syndrome. $N$. Engl. J. Med. 304:192-196.

3. Merritt, T. A., C. G. Cochrane, K. Holcomb, B. Bohl, M. Hallman, D. K. Edwards, and L. Gluck. 1983. Elastase and $\alpha_{1}$-proteinase inhibitor activity in tracheal aspirates during respiratory distress syndrome. Role of inflammation in the pathogenesis of bronchopulmonary dysplasia. J. Clin. Invest. 72:656-666.

4. Cochrane, C. G., R. G. Spragg, and S. D. Revak. 1983. Studies on the pathogenesis of the adult respiratory distress syndrome: evidence of oxidant activity in bronchoalveolar lavage fluid. J. Clin. Invest. 71:754761.

5. Gadek, J. E., G. B. Fills, and R. G. Crystal. 1979. Cigarette smoking induces functional antiprotease deficiency in the lower respiratory tract of humans. Science (Wash. DC). 206:1315-1316.

6. Janoff, A., L. Raju, and R. Dearing. 1983. Levels of elastase activity in bronchoalveolar lavage fluids of healthy smokers and nonsmokers. Am. Rev. Respir. Dis. 127:540-544.

7. Niederman, M. S., L. Fritts, R. B. Fick, W. W. Merrill, R. A. Matthay, J. B. L. Gee, and H. Y. Reynolds. 1982. Detection of a free metalloproteinase elastase in human lung lavage fluid. Am. Rev. Respir. Dis. 125:S212.

8. Janoff, A., B. Sloan, G. Weinbaum, V. Damiano, R. A. Sandhaus, J. Elias, and P. Kimbel. 1977. Experimental emphysema produced by purified human neutrophil elastase: tissue localization of the instilled protease. Am. Rev. Respir. Dis. 115:461-478.

9. Johnson, K. J., J. C. Fantone III, J. Kaplan, and P. A. Ward. 1981. In vivo damage of rat lungs by oxygen metabolites. J. Clin. Invest. 671:983-993.

10. Shasby, D. M., K. M. Vanbenthuysen, R. M. Tate, S. S. Shasby, I. McMurtry, and J. E. Repine. 1982. Granulocytes mediate acute edematous lung injury in rabbits and in isolated rabbit lungs perfused with phorbol myristate acetate: role of oxygen radicals. Am. Rev. Respir. Dis. 125:443-447.

11. Till, G. O., K. J. Johnson, R. Kunkel, and P. A. Ward. 1982. Intravascular activation of complement and acute lung injury: dependency on neutrophils and toxic oxygen metabolites. J. Clin. Invest. 69:1126-1135.

12. Ward, P. A., G. O. Till, R. Kunkel, and C. Beauchamp. 1983. Evidence for role of hydroxyl radical in complement and neutrophildependent tissue injury. J. Clin. Invest. 72:789-801.

13. Till, G. O., K. J. Johnson, and P. A. Ward. 1982. Oxygen-radical dependent lung injury following thermal injury of skin. Fed. Proc. (41):2897. (Abstr.)

14. McConahey, P. J., and F. J. Dixon. 1966. A method of trace iodination of proteins for immunologic studies. Int. Arch. Allergy. 29:185189.

15. Lowry, O. H., N. J. Rosebrough, A. L. Farr, and R. J. Randall. 1951. Protein measurement with the folin phenol reagent. J. Biol. Chem. 193:265-275.

16. Steinman, R. M., and Z. A. Cohn. 1972. The interaction of soluble horseradish peroxidase with mouse peritoneal macrophages in vitro. J. Cell Biol. 55:186-204.

17. Hein, W. G., D. Appleman, and H. T. Pyfrom. 1956. Effects of 3-amino-1,2,4-triazole (AT) on catalase and other compounds. Am. J. Physiol. 186:19-26.

18. Margoliash, E., A. Novogrodsky, and A. Schejter. 1960. Irreversible reaction of 3-amino-1:2:4 triazole and related inhibitors with the protein of catalase. Biochem. J. 74:339-348.

19. Sinet, P. M., R. E. Heikkila, and G. Cohen. 1980. Hydrogen peroxide production by rat brain in vivo. J. Neurochem. 34:1421-1428

20. Aebi, H. 1974. Catalase. In Methods of Enzymatic Analysis. H. Bergmeyer, editor. Verlag Chemie, Weinheim. 2:673-684.

21. Stansell, M. J., and H. F. Deutsch. 1965. Preparation of crystalline erythrocytes. J. Biol. Chem. 240:4299-4305.

22. Brehe, J. E., and H. B. Burch. 1976. Enzymatic assay for glutathione. Anal. Biochem. 74:189-197.

23. Nicholls, P. 1972. Activity of catalase in the red cell. Biochim. Biophys. Acta. 279:306-309.

24. Margoliash, E., and A. Novogrodsky. 1958. A study of the inhibition of catalase by 3-amino-1:2:4-Triazole. Biochem. J. 68:468-475.

25. Kellogg, E. W., and J. Fridovich. 1977. Liposome oxidation and erythrocyte lysis by enzymically generated superoxide and hydrogen peroxide. J. Biol. Chem. 252:6721-6726.

26. Freeman, B. A., and J. D. Crapo. 1982. Biology of disease: free radicals and tissue injury. Lab. Invest. 47:412-426. 
27. Willis, R. J., and C. C. Kratzing. 1972. Changes in levels of tissue nucleotides and glutathione after hyperbaric oxygen treatment. Aust. J. Exp. Biol. Med. Sci. 6:725-729.

28. Nishiki, K., D. Jamieson, N. Oshino, and B. Chance. 1976. Oxygen toxicity in the perfused rat liver and lung under hyperbaric conditions. Biochem. J. 160:343.

29. Sies, H., C. Gerstenecker, H. Menzel, and L. Flohe. 1972. Oxidation in the NADP-system and release of GSSG from hemoglobinfree perfused rat liver during peroxidative oxidation of glutathione by hydroperoxides. FEBS (Fed. Eur. Biochem. Soc.) Lett. 27:171-175.

30. Oshino, N., and B. Chance. 1977. Properties of glutathione release observed during reduction of organic hydroperoxide, demethylation of aminopyrine and oxidation of some substances in perfused rat liver and their implications for the physiological function of catalase. Biochem. J. 162:509-525.

31. Sies, H., and K. H. Summer. 1975. Hydroperoxide metabolizing systems in rat liver. Eur. J. Biochem. 57:503-512.

32. Kosower, N. S., and E. M. Kosower. 1978. The glutathione status of cells. Int. Rev. Cytol. 54:109-160.

33. Gilbert, H. F. 1982. Biological disulfides. The third messenger: modulation of phosphofructokinase activity by thiol/disulfide exchange. J. Biol. Chem. 257:12086-12091.

34. Kondo, T., G. L. Dale, and E. Beutler. 1980. Glutathione transport by inside-out vesicles from human erythrocytes. Proc. Natl. Acad. Sci. USA. 77:6359-6362.

35. Fridovich, I. 1976. Oxygen radicals, hydrogen peroxide, and oxygen toxicity, free radicals. In Biology. W. A. Pryor, editor. Academic Press, Inc., New York. 1:239-277.

36. Bielski, B. H. J., R. L. Arudi, and M. W. Sutherland. 1983. A study of the reactivity of $\mathrm{HO}_{2} / \mathrm{O}_{2}$ with unsaturated fatty acids. J. Biol. Chem. 258:4759-4761.
37. Simon, R. H., C. H. Scoggin, and D. Patterson. 1981. Hydrogen peroxide causes the fatal injury to human fibroblasts exposed to oxygen radicals. J. Biol. Chem. 256:7181-7186.

38. Weiss, S. J., J. Young, A. F. LoBuglio, and A. Slivka. 1981. Role of hydrogen peroxide in neutrophil-mediated destruction of cultured endothelial cells. J. Clin. Invest. 68:714-724.

39. Klebanoff, S. J., and R. A. Clark. 1975. Hemolysis and iodination of erythrocyte components by a myeloperoxidase-mediated system. Blood 45:699-707.

40. McCord, J. M., and E. D. Day. 1978. Superoxide-dependent production of hydroxyl radical catalyzed by iron EDTA complex. FEBS (Fed. Eur. Biochem. Soc.) Lett. 86:139-142.

41. Brawn, K., and I. Fridovich. 1981. DNA strand scission by enzymically generated oxygen radicals. Arch. Biochem. Biophys. 206:414 419.

42. Mead, J. F. 1976. Free radical mechanisms of lipid damage and consequences for cellular membranes. In Free Radicals in Biology W. A. Pryor, editor. Academic Press, Inc., New York. 1:51-68.

43. Ilan, Y. A., A. Crazapski, and D. Meisel. 1976. The one-electron transfer redox potentials of free radicals. I. The oxygen/superoxide system. Biochim. Biophys. Acta. 430:209-224.

44. Cochrane, C. G., and B. A. Aikin. 1966. Polymorphonuclear leukocytes in immunologic reactions: the destruction of vascular basement membrane in vivo and in vitro. J. Exp. Med. 124:733-752.

45. Hawkins, D., and C. G. Cochrane. 1968. Glomerular basement membrane damage in immunological glomerulonephritis. Immunology. 14:665-681.

46. Baehner, R. L., L. A. Boxer, J. M. Allen, and J. Davis. 1977. Autooxidation as a basis for altered function by polymorphonuclear leukocytes. Blood. 50:327-335. 